\title{
Acquisition of Innovative and Entrepreneurial Skills in Basic Science Education for Job Creation in Nigeria
}

\author{
Maryrose Chinwe Mbanefo ${ }^{1 *}$, Obiajulu C Eboka ${ }^{2}$ \\ ${ }^{1}$ Federal Ministry of Education, Abuja, Nigeria, ${ }^{2}$ National Open University of Nigeria, Asaba Delta State, Nigeria \\ *Corresponding Author: mbanefomaryrose@yahoo.com
}

\section{ABSTRACT}

Innovative and entrepreneurial skill acquisition in Nigeria entails focusing on what should be done to bridge the gap between the school and labor market, where the learner will work after graduation, so as to be self-reliant in the society. Specifically, the study determined: The innovative and entrepreneurial skills needed in basic science education for job creation and the teaching strategies required. The study was carried out in Nigeria and was guided by three research questions (RQs). A descriptive survey research design was adopted. The population of the study was made up of 441 principals and 4340 basic science teachers. The instrument used for data collection was a 22-item questionnaire. Mean and standard deviation statistics were used to address the three RQs. The findings revealed that a lot of skills were needed in science education for job creation, the teachers were required to use practically oriented methods in teaching the students, and a lot of factors posed challenges to the acquisition of entrepreneurial skills in basic science education. Consequently, the study made recommendations.

KEY WORDS: basic science; innovativeness; entrepreneurial skills; job creation

\section{INTRODUCTION TO THE PAPER AND REVIEW OF RELEVANT LITERATURE}

几

The Federal Republic of Nigeria recognized the immense role of the development of entrepreneurial skills at the basic school level when it noted that basic education should provide science and technological skills for economic development (FRN, 2004). Therefore, the quality of instructional delivery should be oriented toward inculcating the right type of value and attitude in the students. In addition, the acquisition of appropriate skills and the development of mental, physical, and social abilities/competencies were necessary for the individual to live in and contribute to the development of the society.

Basic science education is that aspect of education that lays the foundation for sustaining lifelong learning. It involves the acquisition of innovative skills and application of the knowledge of science that leads to particular occupations and for the improvement of man's environment (Onwuachu and Okoye, 2012). This includes workforce training in professional areas such as engineering, pharmacy, agriculture, business, and home economics. One of the pillars of the Nigeria National Economic Empowerment and Development Strategy (NEEDS) is "growing in the private sector." Consequently, Nigeria like other nations has accepted this market-driven or private sectorled economy as the model to achieve rapid economic growth and development, efficient resource allocation, and utilization.

It was also recommended by the World Economic Forum (2011) that governments should improve their entrepreneurial ecosystem by bringing entrepreneurship to the classroom so that every student in the basic, secondary, and tertiary level of education should learn entrepreneurial principles, welcome new ideas, and give support to all types of entrepreneurs. The initiative taken by the Nigerian government to encourage entrepreneurial activity includes the infusion of entrepreneurship education into the basic education curriculum and developing up to 34 trade subjects in the post-basic education curriculum, of which senior secondary school students must learn at least one of them before graduation. To this effect, all institutions in the country are required to incorporate entrepreneurship programs into their curriculum and provide young people the opportunity to acquire an entrepreneurial orientation and skills. This infusion of entrepreneurial studies into basic science education is meant to provide the young science and technical students the mind-set for creating and sustaining innovations. Such an infusion might also produce the necessary hub for job creation, poverty reduction, and possibly launch Nigeria into the production market. The $17^{\text {th }}$ Commonwealth Conference of Education Ministers in 2009 led to the restructuring of school curriculum jointly by the Universal Basic Education Commission and the Nigeria Educational Research and Development Council to reflect these community needs and aspirations. Even the curriculum review for primary and secondary schools reflects the government's reforms as spelt out in the NEEDS, which has its focus on poverty reduction, wealth creation, and employment generation.

Innovativeness is the ability of introducing or using new ideas or ways of doing things. The process of innovation involves thinking creatively: Using imagination to manipulate 
instruments or variables, to formulate models, to discover possibilities, and to construct objects and images that never existed before. Innovation can be a change made in established laws and practices by the introduction of something new, with the purpose of improving quality, quantity, output, or procedures. Mbanefo and Chiaha (2014) stated that innovative learning environments focus on the facilitation and utilization of new knowledge acquisition modes, adoption of problemsolving strategies, integration of knowledge from diverse sources, utilization of self-directed learning, and knowledge extension through elaborate creative expression.

While entrepreneurial skills are business skills, which an individual acquires personally to function effectively in business as an entrepreneur and be self-reliant (Umunadi, 2014; Nwafar, 2009). The skills consist of effective utilization of ideas, information, and facts that help a learner develop competencies, services, or become productive employees of organizations. Entrepreneurship has to do with a system of ideas and values that are not ordinarily treated as part of the curriculum, it is the process of using private initiative to transform a business concept into a new venture or to grow and diversify an existing venture or enterprise with high growth potential (Mkpa, 2014; Ugwoke and Abidde, 2014). Therefore, entrepreneurship could be seen as the act of identifying, initiating, organizing, and bringing an idea or vision to life, be it a new product, service, process, strategy, or market. It is all about self-employment, which is very important for improving an individual's quality of life and national development. Consequently, entrepreneurship education leads to the acquisition of entrepreneurial skills for efficient and effective living; it gives the youths more opportunities to exercise creative freedom, higher self-esteem, and a greater sense of control over their own lives.

An entrepreneur is one who undertakes the risk of organizing and managing a business. The entrepreneur looks inward into his/her environment to identify problems confronting people (or business opportunities) and introduces new products and services for the purpose of making profit (Ugwoke and Abidde, 2014). Moemeke (2013) stated that an entrepreneur is, therefore, not only an innovator but also a lifelong learner, a creative person, an initiator, and a potential industrialist. Thus, the destiny of nations lies with the entrepreneurs since they shape, actualize, and bring the developmental dreams and economy of any nation to reality. Therefore, it becomes eminent that entrepreneurial skills should be inculcated into the basic science curriculum for the youths. Consequently, the basic science curriculum, which is in use in Nigeria for science teaching and learning, has built-in strategies where learners are required to be involved in inquiry and related activities that can develop critical and creative thinking skills, in junior secondary schools. Thus, the objectives of basic science and technology curriculum (revised 2012) are to enable learners to: Develop interest and acquire basic skills in science and technology, apply their scientific and technological knowledge and skills to meet societal needs, take advantage of the numerous career opportunities offered by science and technology, and become prepared for further studies in science and technology. The themes that form the integrating threads for the curricula are basic science, basic technology, physical and health education, and information technology, while the sub-themes for basic science are as follows: Learning about our environment; you and energy; and science and development. One of the concepts infused into the curriculum content from primary to junior secondary school is entrepreneurship education (Nigeria Educational Research and Development Council, 2009).

Various types of skills are required for the students to be successful entrepreneurs. Igbo and Hisrich in Umunadi (2014) identified many categories of competencies or skills needed for success in entrepreneurship such as managerial, accounting and financial competencies, marketing and sales skills, and general business skills. The inclusion of these skills into the basic science education program will reduce the rate of dependence on government for job, instill in the students the right mindset, the ability to be creative, and innovative, and be able to create job out of their chosen career. Moemeke (2013) stated that innovative skills in science singularly can not only produce individuals with useable skills but also without the necessary initiative and impetus for utilizing them at the functional level enough to create wealth.

The implementations of innovative and entrepreneurial skills infusion into basic science education curriculum are as follows:

- The implementation of the content of basic science education curricula will change to link training for job creation and employment

- The teachers need to be trained on the strategies for imparting of these skills to students; and provision of the necessary facilities required for the development of business mindset and knowledge in the business world

- The science entrepreneurs need to thrive in entrepreneurial physical environment, which has four elements according to the World Economic Forum (2011), namely, personal enablers, financial enablers, business enablers, and environmental enablers. Some of these enablers are either few or ineffective in Nigeria because of the population of the country. Personal enablers are adviser/mentors and education (formal and informal), while the advisers are people, experienced entrepreneurs that are willing to share knowledge and their experience. They can offer moral support and be a source of motivation for the young entrepreneur to take a risk in starting the business. Seminars and workshop can offer informal education while the schools offer entrepreneurship courses to nurture the entrepreneurial spirit and give students the skills to start a successful venture. Entrepreneurship spirit arises at the early age of life and can be highly encouraged by the educational system which can guide the students and help innovation spread.

Financial enablers are those who commit their money for the entrepreneur to create and grow the business. These include the 
banks, equity investors, and small and medium entrepreneur (SME) financing, microfinancing, and government programs. Equity investors are those who are willing to invest in the venture; they are friends and family members and associates. The bank requires collaterals, a lengthy approval process and proven track records; in addition, there is also a high interest rate to pay the bank. All these can be a burden to the starter. Nwafo (2013) recommended that there is a need for the government to develop a policy framework for banks to set aside a certain percentage of funds to support SME as is done for agriculture. Business enablers are professional that provides the required professional and technical support. These include the professional services, incubator, and network associates. The entrepreneur may need all these experts depending on the nature of the business to serve as mentors and advisers and help them to tackle business challenges. Environmental enablers are the regulatory framework, infrastructure, and culture that are prevailing against the entrepreneurs. The government agencies and chambers of commerce can stimulate entrepreneurship by simplifying rules and providing incentives for starters. The cost of issuing a certificate of occupancy $(\mathrm{C}$ of $\mathrm{O})$ can be reduced to serve as collateral for bank loan. The Nigerian government has reduced a lot of regulatory framework to encourage entrepreneurs, such as the time of registration by the Corporate Affairs Commission (CAC), which is now 11 days as opposed to the previous 21 days. Although getting the license from some regulatory agencies such as the National Agency for Food and Drug Administration and Control and CAC is expensive, time-consuming, and frustrating. The existing infrastructure includes power and energy supply, which is a big challenge for many start-up entrepreneurs. Some of the roads for transportation are not good and are unsafe and public transport such as buses and railways are inadequate. However, there is still hope for improvement in Nigeria since the government has privatized the power sector and is trying to improve the railway. The Nigeria culture of preferring whitecollar jobs to building up business poses a problem to the promotion of entrepreneurship. Most parents do not encourage a child's entrepreneurial spirit and aspiration because of lack of security and prestige (that is their belief), low esteem, and remuneration for skilled workers. The media does not promote entrepreneurship enough. They need to have programs in the television, columns in the magazines, and newspapers. These can help change attitudes and inspire young entrepreneurs so as to showcase new innovations.

Other countries' perspectives on entrepreneurship include, for example, the United States of America's Bridging Disciplinary Program (BDP) at the University of Texas. The BDP runs interdisciplinary programs that focus on creativity in all fields, and they combine courses from business, communication, fine arts, and liberal arts for students to learn how ideas/ inventions and talents/skills are developed and transformed into commercial ventures (BDP, 2016). The Scientific Technology and Innovation (STI) Policy Review of Thailand has fundamental goals that are to offer an up-to-date assessment of the framework conditions and interactions that characterize Thailand's national innovation system and to provide a number of recommendations for strengthening policies and measures that will improve national technological capabilities and encourage innovation in small-scale agriculture and promoting the development of human resources in STI (United Nation Conference on Trade and Development, 2015).

\section{The Problem}

Despite the clamor for self-reliance and job creation in Nigeria, the planning of basic science education in the country has not given enough attention to quality, relevance, and functionality of education. This is evident in students that have graduated from the junior secondary schools that are not yet self-reliant and cannot even do anything for themselves (Double Gist, 2017). Second, although it is basic science education that prepares the students for post-basic and tertiary education, the planning of education for job creation has been shifted to the last two levels of education (the post-basic and tertiary levels). Consequently, the need to investigate the innovative and entrepreneurial skills integrated into basic science education and see how the skills are being imparted to the students for job creation. The study assessed the opinion of the principals and the teachers on the acquisition of innovative and entrepreneurial skills in basic science education for job creation. Specifically, the study sought to determine the innovative and entrepreneurial skills needed in basic science education for job creation, the teaching strategies required for the acquisition of innovative, and entrepreneurial skills in basic science education and the factors that pose challenges for the acquisition of entrepreneurial skills in basic science education for job creation.

\section{Research Questions (RQs)}

To guide this study, the following RQs were proposed.

1. What are the innovative and entrepreneurial skills needed in basic science education for job creation?

2. What are the teaching strategies required for the acquisition of innovative and entrepreneurial skills in basic science education?

3. What are the factors that pose challenges for the acquisition of entrepreneurial skills in basic science education for job creation?

\section{Hypothesis}

$\mathrm{H}_{01}$ : There is no significant difference in the responses of the principals and teachers on the factors that pose challenges for the acquisition of entrepreneurial skills in basic science education for job creation.

\section{METHOD AND PROCEDURE}

Delta state in the south-south geopolitical area of Nigeria was used for the study, and descriptive research design was employed for this study. It is appropriate because it sought to elicit people's opinion on the acquisition of innovative and entrepreneurial skills in basic science education (Ary 
et al., 2010). The population of the study comprises all of the 441 public junior secondary schools principals and the 4340 science teachers in Delta State (Ministry of Basic and Secondary Education: Delta State Nigeria, 2015). 10\% of the population was selected through simple random sampling technique (44 principals were selected from the 441 public schools and 440 science teachers from the 4340 number of science teachers in the state). The respondents were 440 science teachers directly involved in teaching students basic science and technology and 44 principals that are involved in the school management: Capacity building of teachers and procuring the facilities for instruction.

\section{Survey Instrument}

The questionnaire used for the study is structured based on the RQ. It is divided into three clusters (1-3) and has a total of 22 items, with 4-point Likert scale options (strongly agree, agree, disagree, and strongly disagree), weighing of 1-4 for favorable statements. Cluster 1 contains 9 items addressing RQ 1; cluster 2 contains 5 items addressing RQ 2; and cluster 3 contains 8 items addressing RQ 3. It was validated by two experts, and pilot tested to obtain the reliability coefficient. The Cronbach's alpha $(\alpha)$ coefficient was 0.85 . The data collected from the respondents were analyzed to answer the RQs. These were assigned weights of 4:3:2:1 for favorable statements. The data were analyzed by computing the mean and standard deviations (SDs) for each item. The researchers used the real limits to interpret the results based on the following decision rule. Any item with a mean score $<2.50$ was not accepted, while any that scored above 2.5 was accepted. The SDs were also presented to show how the individual raw scores from the computed mean were dispersed. The t-test statistics were used in testing the null hypothesis at 0.05 level of significance.

\section{RESULTS}

The results are presented in Tables 1-3 showing the summary of the results of the three sections of the study. The tables reported the mean and SD for each of the items on which the decision regarding the RQs was based. Table 3 also contains the summary of the t-test analysis of the difference between the mean of the responses of the teachers and the principals to address the hypothesis.

\section{RQ One}

What are the innovative and entrepreneurial skills needed in basic science education for job creation?

Table 1 shows the mean ratings and SD of the teachers and the principals' responses on the innovative and entrepreneurial skills needed in basic science education for job creation. The cluster mean of 3.22 revealed that the respondents strongly agreed that all the skills were needed in basic science education for job creation. The table revealed that the items had their SD range from 0.56 to 0.70 , which indicated that the respondents were close to the mean and one another in their responses. The cluster SD of 0.64 shows that the degree of variance from the mean is not much.

\section{RQ Two}

What are the teaching strategies required for the acquisition of innovative and entrepreneurial skills in basic science education?

Table 2 shows the mean ratings and SD of the teachers and the principals' responses on the teaching strategies required for the acquisition of innovative and entrepreneurial skills in basic science education. There are 5 items in the cluster, and only one of them has a mean rating of 2.22. The cluster mean of 3.12 revealed that all the teachers and the principals agreed that all the teaching strategies were required for the acquisition of innovative and entrepreneurial skills in basic science education except for the "use of lecture method." The SD of 0.71 shows that the degree of variance from the mean is not much.

\section{RQ Three}

What are the factors that pose challenges for the acquisition of entrepreneurial skills in basic science education for job creation?

Table 3 shows the mean ratings and SD of the teachers and the principals' responses on the factors that pose challenges for the acquisition of entrepreneurial skills in basic science education for job creation. It revealed that all the teachers and principals agreed that all the factors pose challenges for the acquisition of entrepreneurial skills in basic science education for job creation.

\section{Hypothesis}

There is no significant difference in the responses of the principals and teachers on the factors that pose challenges for the acquisition of entrepreneurial skills in basic science education for job creation.

Table 3 revealed that there was a significant difference in all the items. This was expected considering that the mean for teachers was 3.07 and that of the principals was 3.28. The mean result implies that the principals perceived the items as factors that pose challenges for the acquisition of the skills for job creation more than the teachers. It also showed that the t-calculation for the cluster was 83.49 and the t-tab (critical) value is 1.96 . Thus, the null hypothesis is rejected.

\section{DISCUSSION OF FINDINGS}

RQ one sought to investigate the innovative and entrepreneurial skills needed in basic science education for job creation. The results revealed that the teachers and the principals agreed that innovative and entrepreneurial skills were needed in basic science education for job creation. It was their perception that innovative skills of being independent, imaginative, and constructive; skills for introducing or using new ways of doing things and come up with innovative ideas; business managerial skill for establishing, managing, and sustaining businesses, for example, for record keeping such as inventory of production, sales, purchase, and profit and loss account were needed in the basic science curriculum for job creation. This is in line with the skills identified by Igbo and Hisrich in Umunadi 


\begin{tabular}{|c|c|c|c|}
\hline Item & n & Mean \pm SD & Decision \\
\hline Innovative skills of being independent, imaginative, and constructive thinker & 474 & $3.55 \pm 0.56$ & Accepted \\
\hline Skills for introducing or using new ideas/ways of doing things & 480 & $3.47 \pm 0.61$ & Accepted \\
\hline Skills to be critical to come up with innovative ideas & 464 & $3.14 \pm 0.70$ & Accepted \\
\hline Entrepreneurial skills for recognizing and using tools and materials for production & 476 & $3.36 \pm 0.61$ & Accepted \\
\hline $\begin{array}{l}\text { Collaborative skills (associative partnership) needed for joining corporative societies such as producer and consumer } \\
\text { corporative }\end{array}$ & 476 & $3.17 \pm 0.65$ & Accepted \\
\hline Skills for accessing funds and accounting & 472 & $2.86 \pm 0.70$ & Accepted \\
\hline Personal entrepreneurship skills: Ability to persistently research and find relevant information & 480 & $3.45 \pm 0.61$ & Accepted \\
\hline Ability to organize and build network & 456 & $3.23 \pm 0.67$ & Accepted \\
\hline $\begin{array}{l}\text { Business managerial skill for establishing, managing and sustaining businesses, for example, for record keeping such } \\
\text { as inventory of production, sales, purchase, and profit and loss account }\end{array}$ & 456 & $3.23 \pm 0.69$ & Accepted \\
\hline Cluster summery & 484 & $3.22 \pm 0.64$ & Accepted \\
\hline
\end{tabular}

SD: Standard deviation

\begin{tabular}{|c|c|c|c|}
\hline Item & $\mathbf{n}$ & Mean \pm SD & Decision \\
\hline $\begin{array}{l}\text { Use of multiple modes of inquiry, } \\
\text { for example, guided inquiry }\end{array}$ & 484 & $3.31 \pm 0.73$ & Accepted \\
\hline $\begin{array}{l}\text { Use of students' collaborative } \\
\text { project work }\end{array}$ & 462 & $3.25 \pm 0.67$ & Accepted \\
\hline Use of lecture method & 468 & $2.22 \pm 0.99$ & Not accepted \\
\hline $\begin{array}{l}\text { Use of facilitation technique } \\
\text { that allows for sharing ideas and } \\
\text { freedom to innovate }\end{array}$ & 480 & $3.35 \pm 0.57$ & Accepted \\
\hline $\begin{array}{l}\text { Use of field trips (visit to factories, } \\
\text { etc.) }\end{array}$ & 484 & $3.45 \pm 0.58$ & Accepted \\
\hline Cluster summary & 484 & $3.12 \pm 0.71$ & Accepted \\
\hline
\end{tabular}

(2014). They agreed strongly that the entrepreneurial skills for recognizing and using tools and materials for production and collaborative skills (associative partnership) are needed for joining corporative societies; ability to organize and build a network; personal entrepreneurship skills; ability to persistently research and find relevant information and the skills for accessing funds and accounting. This is in line with Moemeke (2013) who stated that the entrepreneurial aspects of science education should include courses in business innovation, job creation, management of small and medium scale enterprises, accessing of funds/finance sourcing, and introduction to financial accounting.

The findings revealed that the respondents agreed strongly that the teaching strategies required for the acquisition of innovative and entrepreneurial skills in basic science education were the use of multiple modes of inquiry, for example, guided-inquiry; the use of students' collaborative project work; use of facilitation technique that allows for sharing ideas and freedom to innovate; and the use of field trips (visit to factories, etc.,). These are in line with the strategies stated by Adikwu (2015) for inculcating entrepreneurial skills in students at the basic level, which includes: Studentsoriented, teacher-oriented, assignment-oriented, games, and stimulation methods that will help students explore opportunities for innovation and creative ideas through practical and involvement in the activities of industries. Obasi and Ohio (2014) also stated that entrepreneurship education was practically oriented, designed, and packaged to equip the students (beneficiaries) with practical skills, knowledge, and orientation for entrepreneurial life, which was geared toward job creation. It was, therefore, a special training given for the acquisition of vocational, technical skills, management skills, and capacity for self-reliance and employment. Thus, it created job and wealth and reduced unemployment, poverty, corruption, and crime, which the youths were prone to as a result of unemployment. They also disagreed with the use of lecture method.

The findings revealed that the respondents agreed strongly that the following factors posed challenges for the acquisition of entrepreneurial skills in basic science education for job creation: The curriculum that did not contain much room for creative freedom and enough entrepreneurial learning experiences; the lack of awareness of the benefits of entrepreneurial skills acquisition; most teachers are not trained to lead students through the path of productivity, self-reliance, and job creation; and some teachers do not use teaching strategies that foster innovative and entrepreneurship skills acquisition. The teachers teach students theoretical subjects and there is no hands-on teaching required to encourage the students. This is in line with Mbanefo (2015) who stated that standardization and stiff control of curriculum have unfavorable effects on students' creativity and that teachers are not adequately trained. Experienced entrepreneurs are not linked to the schools to motivate and advise students on the entrepreneurship skill acquisition; there is no policy framework for banks to set aside funds to support small and medium enterprises. This is in line with Nwafo (2013) who stated that the well-known Nigerians neither provide forum to reach out to the young starters and advise them nor be their mentors. They also agreed that most parents and teachers do not encourage entrepreneurial spirit and aspiration among children, and there are inadequate facilities and equipment for innovative and entrepreneurial 
Table 3: The factors that pose challenges for the acquisition of entrepreneurial skills in basic science education for job creation

\begin{tabular}{|c|c|c|c|c|c|c|c|}
\hline \multirow[t]{2}{*}{ Item } & $n=484$ & \multirow[t]{2}{*}{ Gp } & \multirow[t]{2}{*}{$\mathrm{n}$} & \multirow[t]{2}{*}{ Mean \pm SD } & \multirow[t]{2}{*}{ t-calculation } & \multirow[t]{2}{*}{$p$ value } & \multirow[t]{2}{*}{ Decision } \\
\hline & Mean \pm SD & & & & & & \\
\hline \multirow{2}{*}{$\begin{array}{l}\text { Curriculum does not contain much room for creative freedom and } \\
\text { enough entrepreneurial learning experiences }\end{array}$} & $2.98 \pm 0.89$ & $\mathrm{~T}$ & 438 & $2.97 \pm 0.89$ & 73.32 & 0.00 & $\mathrm{~S}$ \\
\hline & & $\mathrm{P}$ & 44 & $3.09 \pm 0.92$ & & & \\
\hline \multirow{2}{*}{$\begin{array}{l}\text { Lack of awareness of the benefits of entrepreneurial skills } \\
\text { acquisition }\end{array}$} & $3.01 \pm 0.72$ & $\mathrm{~T}$ & 438 & $3.01 \pm 0.73$ & 91.25 & 0.00 & $\mathrm{~S}$ \\
\hline & & $\mathrm{P}$ & 44 & $3.05 \pm 0.72$ & & & \\
\hline \multirow{2}{*}{$\begin{array}{l}\text { Most teachers are not trained to lead students through the path of } \\
\text { productivity, self-reliance, and job creation }\end{array}$} & $3.07 \pm 0.92$ & $\mathrm{~T}$ & 436 & $3.06 \pm 0.92$ & 72.99 & 0.00 & $\mathrm{~S}$ \\
\hline & & $\mathrm{P}$ & 44 & $3.18 \pm 0.91$ & & & \\
\hline \multirow{2}{*}{$\begin{array}{l}\text { Experience entrepreneurs are not linked to the schools to motivate } \\
\text { and advise students on the entrepreneurship skill acquisition }\end{array}$} & $3.30 \pm 0.75$ & $\mathrm{~T}$ & 438 & $3.29 \pm 0.76$ & 96.12 & 0.00 & $\mathrm{~S}$ \\
\hline & & $\mathrm{P}$ & 44 & $3.41 \pm 0.73$ & & & \\
\hline \multirow{2}{*}{$\begin{array}{l}\text { There is no policy framework for banks to set aside funds to support } \\
\text { small and medium enterprises }\end{array}$} & $3.03 \pm 0.84$ & $\mathrm{~T}$ & 438 & $3.01 \pm 0.84$ & 78.37 & 0.00 & $\mathrm{~S}$ \\
\hline & & $\mathrm{P}$ & 40 & $3.15 \pm 0.87$ & & & \\
\hline \multirow{2}{*}{$\begin{array}{l}\text { There are inadequate facilities and equipment for innovative and } \\
\text { entrepreneurial skill acquisition in schools }\end{array}$} & $3.45 \pm 0.74$ & $\mathrm{~T}$ & 438 & $3.42 \pm 0.76$ & 102.42 & 0.00 & $\mathrm{~S}$ \\
\hline & & $\mathrm{P}$ & 44 & $3.82 \pm 0.39$ & & & \\
\hline \multirow{2}{*}{$\begin{array}{l}\text { Most teachers do not use teaching strategies that foster innovative } \\
\text { and entrepreneurship skills acquisition }\end{array}$} & $2.98 \pm 0.81$ & $\mathrm{~T}$ & 438 & $2.94 \pm 0.81$ & 80.98 & 0.00 & $\mathrm{~S}$ \\
\hline & & $\mathrm{P}$ & 44 & $3.36 \pm 0.66$ & & & \\
\hline \multirow{2}{*}{$\begin{array}{l}\text { Most parents and teachers do not encourage entrepreneurial spirit } \\
\text { and aspiration among children }\end{array}$} & $2.88 \pm 0.86$ & $\mathrm{~T}$ & 438 & $2.85 \pm 0.86$ & 72.44 & 0.00 & $\mathrm{~S}$ \\
\hline & & $\mathrm{P}$ & 44 & $3.18 \pm 0.85$ & & & \\
\hline \multirow[t]{2}{*}{ Cluster summary } & & $\mathrm{T}$ & 438 & $3.07 \pm 0.82$ & 83.49 & 0.00 & $\mathrm{~S}$ \\
\hline & & $\mathrm{P}$ & 44 & $3.28 \pm 0.76$ & & & \\
\hline
\end{tabular}

$\mathrm{Df}=482$, t-tab $=1.96$ at $\mathrm{P}=0.05$. SD: Standard deviation, T: Teachers, P: Principals, Gp: Group

skill acquisition in schools.

In summary, the findings revealed that a lot of innovative and entrepreneurial skills are needed in basic science education for job creation; the teachers are required to use practically oriented methods in teaching the students; but many factors pose challenges to the acquisition of entrepreneurial skills in basic science education for job creation such as curriculum, teacher, and government-related factors.

\section{RECOMMENDATIONS}

The following recommendations are made based on the findings of the study:

1. The scope of the basic science curriculum should be extended to have more entrepreneurial experiences for teachers to lead students through the path of productivity, self-reliant, and job creation.

2. Teachers should be trained to use teaching strategies that foster innovative and entrepreneurship skills acquisition instead of relying so much on lecture method.

3. Government should provide enabling environment (facilities and equipment) that are necessary for creativity and innovation and develop policy frameworks that will encourage network associations, banks, incubators, and professional services to support young science entrepreneurs. All the stakeholders (financial, business and regulatory bodies in Nigeria) should motivate students in the entrepreneurial skill acquisition that will make them employers rather than employees of labor.

\section{REFERENCES}

Adikwu, M.U. (2015). Towards Effective Application of Science, Technology Engineering and Mathematics education research Keynote address for the STAN 56 ${ }^{\text {th }}$ Annual Conference, Awka, Anambra State, Nigeria. Retrieved from: http://www.stanonline.org/index.php. [Last retrieved on $19 \mathrm{Jul} 2017$ ].

Ary, D., Jacob, L.C., Sorensen, O., \& Walker, D. (2010). Introduction to research in education. $9^{\text {th }}$ ed. Belmont, CA: Wadsworth, Cengage Learning.

Bridging Disciplines Program (BDP). (2016). Innovation; Creativity and Entrepreneurship. Austin: University of Texas. Retrieved from: https:// www.utexas.edu/ugs/bdp/program. [Last retrieved from 2017 Jul 19].

DoubleGist. (2017), Adolescent Problems and their Counselling Strategies in Enugu State. Available from: http://www.doublegist.com/adolescentproblems-counseling-strategies-enugu-state. [Last accessed on 2017 Oct 05].

Federal Government of Nigeria (FRN). (2004). National Policy on Education. Lagos: NERDC Press.

Federal Ministry of Education. (2009). Nigeria Country Report. $17^{\text {th }}$ Conference of Commonwealth Ministers of Education, Kuala Lumpur, Malaysia. Retrieved from: http://www.create-rpc.org/pdf documents/ccemaccount.pdf. [Last retrieved from 2017 Jul 19].

Mbanefo, M.C. \& Chiaha, G.T. (2013). Curriculum innovations in science and technology for quality, relevance sustainability in teacher education in Nigeria. In: Onyegaegbu N \& Eze U., (Eds.), Teacher Education in Nigeria: Quality, Relevance and Sustainability. Nsukka: Institute of Education, UNN. pp. 74-85.

Mbanefo, M.C. (2015). Developing creative thinking skills in basic science students: Prospects and challenges. Journal of Science Teachers Association of Nigeria. 50(1), 207-216.

Mkpa, A.M. (2014). Education for global competitiveness in job creation: Inclusion of entrepreneurship in Nigeria higher education: Challenges 
and prospects. International Journal of Educational Research, 13(1), $1-13$.

Moemeke, C.D. (2013). Innovating science education for technical entrepreneurship: The curriculum dimension. Business \& Entrepreneurship Journal, 2(2), 39-46.

Nigeria Educational Research and Development Council. (2009). Junior Secondary School Curriculum: Basic Science and Technology JSS 1-3. Abuja: Sheda.

Nwafo, K. (2013). Accelerating economic development through support for technical, vocational and entrepreneurial education. Education Today. A Journal of the Federal Ministry of Education, 14(1), 1-10.

Nwafor, P.Z. (2007). Practical Approach to Entrepreneurship: Small and Medium Scale Enterprises. Enugu: Precision Publishers Ltd.

Obasi, K.K. \& Ohio, A.N. (2014). Developing foundational entrepreneurship capacity at the basic level for Manpower development in Imo state: The Planning challenges. International Journal of Educational Research, $13(1), 81-92$.
Onwuachu, W.C. \& Okoye, P.O. (2012). Relevance of basic science curriculum for entrepreneurship skill acquisition. Knowledge Review, 26(4), 6-13.

Ugwoke, S.C \& Abidde, E. (2014). Entrepreneurial skill development in basic education for wealth creation. International Journal of Educational Research, 13(1), 65-80.

Umunadi, E.K. (2014). Acquisition of entrepreneurial and technical education skills for global competitive and job creation. International Journal of Educational Research, 13(1), 128-144.

United Nation Conference on Trade and Development. (2015). Science, Technology and Innovation Policy Review - Thailand. Retrieved from: http://unctad.org/en/PublicationsLibrary/dtlstict2015d1_en.pdf. [Last retrieved on 2017 Jul 19]

World Economic Forum. (2011). Nigeria Report. Special meeting on Economic Growth and Job Creation in the Arab world. Retrieved from http://www3.weforum.org/docs/ME11/WEF ME11 Report.pdf. [Last retrieved on 2017 Jul 19]. 